\title{
Brief Report: Training New Zealand Well Child/Tamariki Ora Nurses on Early Autism Signs Using the Social Attention and Communication Surveillance-Revised
}

\author{
Hannah Waddington ${ }^{1}\left[\right.$ Daniel Shepherd ${ }^{2} \cdot$ Larah van der Meer $^{1,3} \cdot$ Naomi Powell-Hector $^{1} \cdot$ Eleanor Wilson $^{1} \cdot$ \\ Josephine Barbaro ${ }^{4}$
}

Accepted: 27 October 2021 / Published online: 8 November 2021

(C) The Author(s), under exclusive licence to Springer Science+Business Media, LLC, part of Springer Nature 2021

\begin{abstract}
Universal developmental surveillance is considered best practice for early identification of autism. We analysed data from 175 New Zealand Well-Child/Tamariki Ora nurses who attended a 1-day training in developmental surveillance for autism using the social attention and communication surveillance-revised (SACS-R) tool. We used a survey to measure nurses' knowledge of typical development, knowledge of early signs of autism, general autism knowledge, and confidence in identifying and discussing early signs, prior to the workshop, after the workshop, and at follow-up. We measured perceived acceptability of the SACS-R after the workshop and at follow-up. Nurses showed improvements on all measures from pre-workshop to post-workshop and pre-workshop to follow-up. Implementation of the SACS-R across different contexts appears feasible and acceptable.
\end{abstract}

Keywords Developmental surveillance · Autism spectrum disorder · Early detection · Early identification · New Zealand · Knowledge

Autism spectrum conditions (referred to herein as autism) are characterised by difficulties with social communication and the presence of restricted and repetitive behaviours and interests (American Psychiatric Association, 2013). It is estimated that as many as one in 54 children have an autism diagnosis (Maenner et al., 2020). Most children can now be reliably diagnosed by the age of two but the average age of diagnosis remains around 4 years or older (Barbaro \& Dissanayake, 2017; Bent et al., 2015; van't Hof et al., 2020).

Hannah Waddington

hannah.waddington@vuw.ac.nz

1 School of Education, Victoria University of Wellington, P.O. Box 600, Wellington 6140, New Zealand

2 Department of Psychology, Auckland University of Technology, Private Bag 92006, Auckland 1142, New Zealand

3 Autism New Zealand, 20 Sydney Street, Petone, Wellington, New Zealand

4 Olga Tennison Autism Research Centre, School of Psychology and Public Health, La Trobe University, Kingsbury Drive, Bundoora, Melbourne, VIC 3086, Australia
Early identification is essential in enabling earlier diagnosis and, thus, access to timely evidence-based early intervention (Whitehouse et al., 2019), which promotes child and family health outcomes (Fuller \& Kaiser, 2019; Zwaigenbaum et al., 2015).

Universal developmental surveillance is recommended best practice for early identification of autism (American Academy of Pediatrics, 2007). It involves the combined use of clinical observations, standardized autism screening tools, and consideration of parental concerns (MozolicStaunton et al., 2020). Child health nurses are ideally placed to conduct developmental surveillance during their regular "well-child checks" in the first 2 to 3 years of a child's life (Oberklaid et al., 2013). Several studies have examined health professionals' knowledge of autism and found that it is generally low, regardless of their level of experience (Atun-Einy \& Ben-Sasson, 2018; Shrestha et al., 2021Tilahun et al., 2019). Thus, child health nurses may benefit from autism-specific training.

The social attention and communication surveillancerevised (SACS-R) is a well-validated instrument used in universal developmental surveillance for autism (Barbaro \& Dissanayake, 2010, 2013; Mozolic-Staunton et al., 
2020). These checklists outline key social attention and communication markers associated with a higher likelihood of an autism diagnosis at the ages of 12, 18, and 24 months (Barbaro \& Dissanayake, 2010, 2013). They focus exclusively on social attention and communication markers, rather than restricted and repetitive behaviours, as these are the most predictive of an autism diagnosis in this age range (Barbaro \& Dissanayake, 2009). Research has been conducted with over 300 Maternal and Child Health $(\mathrm{MCH})$ nurses in Australia who were trained to implement the SACS-R during their routine well-child checks. Barbaro and Dissanayake (2010) found that, when used between 12 and 24 months, the SACS-R had a positive predictive value (PPV) of $81 \%$ with estimated sensitivity of $83 \%$ and specificity of $99.8 \%$. Mozolic-Staunton et al. (2020) reported similar findings with the SACS-Revised (84\% PPV; 99\% Negative Predictive Value; 82\% Sensitivity; $99 \%$ Specificity). This is higher than other common autism screening tools such as the Modified Checklist for Autism in Toddlers (pooled specificity of 51\%, sensitivity of $83 \%$, and PPV of $6 \%$ in community populations; Yuen et al., 2018) and the autism pathway of the Parents Evaluation of Developmental Status (Mozolic-Staunton et al., 2020).

Nurses appear to view the SACS-R tool and training positively. Barbaro et al. (2011) reported that, immediately following training and at follow-up 6-9 months later, $\mathrm{MCH}$ nurses found the SACS-R tool to be useful, positive, and easy to implement. Shreshta et al. (2021) similarly reported that Female Community Health Volunteers in Nepal found the SACS-R tool to be highly acceptable. Following the training, they also improved in their knowledge of typical development and signs of autism, and their confidence in monitoring and referring children with a higher likelihood of autism.

Prior to large-scale implementation, it is important to ensure that tools for developmental surveillance are suited to the needs and context of different settings and countries. In New Zealand (NZ), well-child checks are conducted by Well-Child/Tamariki Ora (WCTO) nurses as a free, universal public health-care service through Plunket and other providers. Therefore, WCTO nurses are ideal candidates to implement developmental surveillance for autism in NZ, although no such programme is currently in place.

The current study aimed to determine whether a 1-day training for WCTO nurses in developmental surveillance for autism using the SACS-R tool was acceptable and feasible in a NZ context. The specific research questions were:

1. Did nurses' knowledge of typical social attention and communication development, early signs of autism, and autism more generally improve immediately following the training and at follow-up?
2. Did nurses' confidence in administering the SACS-R and in raising concerns with parents improve immediately following the training and at follow-up?

3. Did the nurses find the training and the SACS-R tool to be acceptable immediately following the training and at follow-up?

4. Was there any relation between the amount of time participants had spent in their role or as a registered nurse and: (1) their knowledge of autism and typical development, and (2) their confidence in identifying early signs of autism and raising them with parents?"

\section{Method}

\section{Ethical Clearance and Informed Consent}

Ethical clearance was granted by the Victoria University of Wellington Human Ethics Committee (\#27192). The first author explained the study at the start of the workshop, with attendees reading the information sheet prior to consenting. Participation was voluntary and responses were confidential.

\section{Eligibility}

To be included participants needed to: (a) have attended one of the workshops, (b) be employed by Plunket or another WCTO provider, and (c) be a registered nurse.

\section{Setting and Context}

The first workshop was conducted at the Porirua Campus of Whitirea, Wellington in June 2019, with a further two workshops at the North and South campuses of the Auckland University of Technology, Auckland in November 2019. WCTO nurses work with the majority of NZ infants and conduct checks five times in their first year of life and again at 15-18 months, 2-3 years, and 4 years. All participants at both workshops were invited to participate in the survey, if they met eligibility criteria.

\section{Design}

This study used a non-experimental pre-test, post-test, follow-up survey design.

\section{Time-Points}

Participants completed the pre- and post-tests surveys on the day of the workshop, while the follow-up survey was distributed 3 months later for the Wellington cohort, and 8 months later for the Auckland cohort. This was due to the initial follow-up falling during a period of Covid-19 lockdown. 


\section{Measures}

The pre- and post-workshop surveys were primarily completed on paper and the follow-up survey was completed online through Qualtrics. The current survey was adapted from Shrestha et al. (2021). Cronbach's alpha for the subscales in this study ranged from 0.62 (early signs) to 0.91 (confidence). Fewer questions were included in the Auckland survey than the Wellington survey because, following the Wellington workshop, some nurses reported that the survey was onerous to complete. We retained those questions that were deemed by a developer of the SACS-R (JB), to most accurately reflect the content of the workshop and the tool. Further, for the Knowledge of Early Signs subscale only the Auckland data is reported as the Wellington survey did not include all relevant questions for this subscale. For all other subscales data from both the Wellington and Auckland surveys are reported. Some questions on this subscale were altered for the Auckland workshop because several items related to restricted and repetitive behaviours and were, thus, not deemed to be reflective of overall participant learning. Although restricted and repetitive behaviours were covered in the workshops, the core focus, including all items in the SACS-R checklist, was on social communication. Thus, only those questions included in both the Wellington and Auckland surveys are reported, while the Knowledge of Early Signs subscale is reported for Auckland only as too few questions remained in the Wellington survey once the restricted and repetitive behaviour items were removed. Demographic information was collected in the pre-workshop survey. The survey contained the following subscales (all items are listed in Tables 2 and 3):

\section{Knowledge}

The Knowledge of Typical Development subscale included six items regarding the age when children would typically meet early social attention and communication milestones. Participants were required to select the correct age from four age ranges or to select "unsure". The Knowledge of Early Signs subscale included seven behaviours seen in young children, with participants indicating whether each behaviour was, or was not, a key sign of autism. The General Autism Knowledge subscale included six statements regarding conceptions and misconceptions of autism. Participants indicated whether each statement was true or false or that they did not know. Correct responses received scores of "1" and incorrect responses received scores of "0". Scores were summed to provide an indicator of overall knowledge for each subscale.

\section{Confidence}

This subscale included four items about participants' confidence in identifying early signs of autism and one item about confidence in discussing concerns with parents. Participants rated their agreement with each statement using a Likert-type scale ( $1=$ strongly disagree; $5=$ strongly agree) where higher scores indicated greater confidence. Overall confidence was indicated by participants' mean scores across all five items.

\section{Acceptability of the SACS-R Tool}

This subscale was only administered post-workshop and at follow-up. It included five items about participants' perceptions of the feasibility and acceptability of the SACS-R tool. Scoring was the same as the Confidence subscale.

\section{Procedure}

The workshops were delivered by the senior author (JB) and lasted for 4.5 to $5 \mathrm{~h}$ excluding breaks. The workshops covered typical and atypical social attention and communication, the importance of early identification and diagnosis, early signs of autism (including video comparisons of autistic and non-autistic children), administering the SACS-R tool, and discussing concerns with parents. The workshop involved PowerPoint slides, videos, handouts, and group tasks. Local clinicians and representatives from Autism NZ also shared information about referral and local support services. More details of the training are reported in Barbaro et al. (2011).

\section{Data Analysis}

Analyses were conducted in SPSS (v. 27). Descriptive statistics were calculated for demographic characteristics, subscales and item-level responses. The subscale scores were not normally distributed, so non-parametric inferential tests were used. Data from Auckland and Wellington were analysed together as Mann-Whitney U tests indicated there were no significant differences in subscale scores between these two locations. As comparatively few participants completed follow-up, Wilcoxon signed rank tests were used to determine the significance of changes in subscale scores from pre-workshop to post-workshop, pre-workshop to follow-up, and post-workshop to follow-up. Here the alpha level was reduced to 0.017 to correct for multiple comparisons. Spearman's correlations were used to examine the relations between participant demographic characteristics (time in role/as a nurse) and subscale scores. Values from 0.1 to 0.3 were considered weak, values from 0.3 to 0.5 were moderate, and values from 0.5 to 1 were strong (Cohen, 
1988). When participants completed $\geq 50 \%$ of items for a particular subscale but some responses were missing, data was imputed for the remaining items based on their mean score for that subscale. Twenty-four participants had a least one score imputed and imputation occurred for between 0 and 18 participants across subscales and time points (pre-, post- and follow-up).

\section{Results}

\section{Demographic Characteristics}

One-hundred-and-eighty-eight individuals completed at least one of the pre and post surveys on the day of the workshop. Except for several clinical leaders and educators who did not intend to use the SACS-R in practice, this number represented all nurses who attended the Auckland and Wellington workshops. However, eleven individuals were excluded because they were not registered nurses, and two

Table 1 Demographic characteristics of participants $(n=175)$

\begin{tabular}{lll}
\hline Characteristic & $n(\%) / M(S D)$ & Missing $(n)$ \\
\hline $\begin{array}{l}\text { Gender } \\
\text { Female }\end{array}$ & $175(100 \%)$ & 0 \\
Location & \\
Auckland & $132(75.4 \%)$ & 0 \\
Wellington & $43(24.6 \%)$ & \\
Role & & \\
Nurse & $140(80.0 \%)$ & 0 \\
PlunketLine nurse & $13(7.4 \%)$ & \\
Clinical leader & $15(8.5 \%)$ & \\
Educator & $3(1.7 \%)$ & 22 \\
Other & $4(2.3 \%)$ & 5 \\
Mean years in role & 7.2 years $(6.7$ years $)$ & \\
Mean years registered as & 18.1 years $(12.3$ years $)$ & \\
a nurse & \\
\hline
\end{tabular}

were excluded due to incomplete pre-workshop data, leaving 175 participants. Also, only 56 individuals completed the follow-up survey, resulting in a response rate of $32 \%$ for the follow-up survey. Table 1 shows the participant demographic characteristics.

\section{Knowledge}

Figure 1 shows the mean percentage of correct knowledge items for each subscale, while Table 2 shows the percentage of participants who answered each knowledge item correctly.

Wilcoxon signed ranks tests revealed significant improvement in participants' knowledge of typical development, knowledge of early signs, and general autism knowledge from pre-workshop to post-workshop $(Z=4.542, p<0.001$; $Z=6.722, p<0.001$; and $Z=9.699, p<0.001$ respectively) and pre-workshop to follow-up $(Z=3.266, p=0.001$; $Z=3.794, p<0.001$; and $Z=4.354, p<0.001$ respectively). There was no significant change from post-workshop to follow-up for participants' knowledge of typical development or knowledge of early signs $(Z=-0.960, p=0.337$; and $Z=-0.288, p=0.774$ respectively). There was a significant decrease in participants' general autism knowledge from post-workshop to follow-up, although this remained above pre-workshop levels $(Z=-3.486, p<0.001)$. Table 2 indicates that the percentage of participants who selected the correct response increased for almost all items from preworkshop to post-workshop and follow-up and decreased for most items from post-workshop to follow-up across all three knowledge domains.

\section{Confidence}

Table 3 shows participants' mean Likert scale scores for each confidence item and Fig. 2 shows their overall confidence at each time-point. Overall participant confidence increased significantly from pre- to post-workshop $(Z=10.887$, $p<0.001)$ and follow-up $(Z=6.767, p<0.001)$, and decreased significantly from post-workshop to follow-up but
Fig. 1 Mean percentage of correct items for knowledge of typical development, knowledge of early signs, and general autism knowledge at pre-workshop, post-workshop, and follow-up. Note: $* * p<0.001$

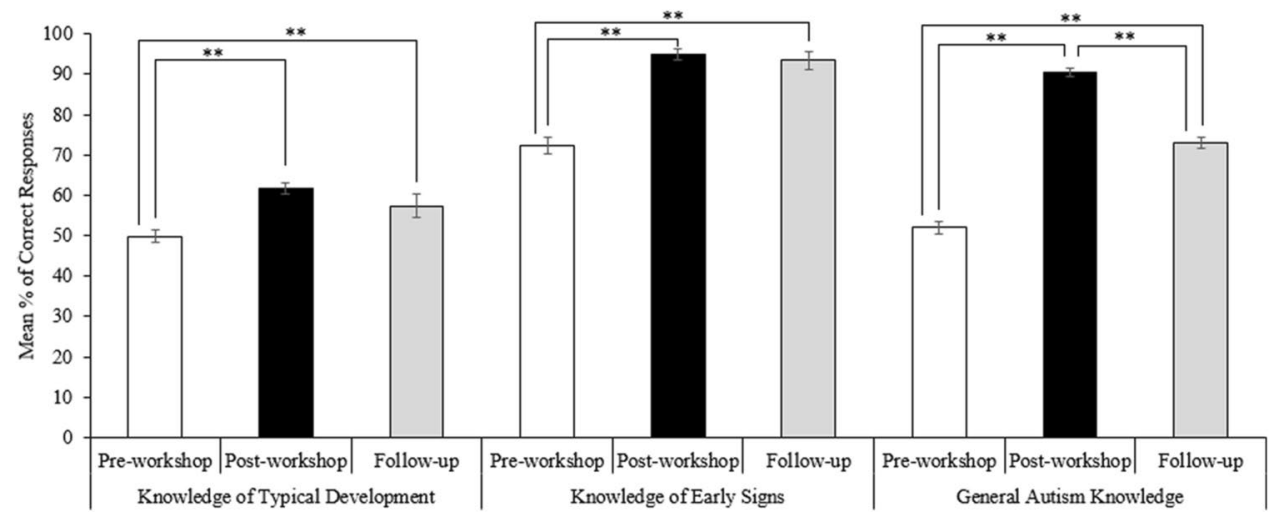


Table 2 The percentage of participants who correctly answered each knowledge question at pre-workshop, post-workshop, and follow-up

\begin{tabular}{|c|c|c|c|c|c|c|}
\hline Item & $\begin{array}{l}\text { Pre-work- } \\
\text { shop (\%) }\end{array}$ & $\begin{array}{l}\text { Post-work- } \\
\text { shop (\%) }\end{array}$ & $\begin{array}{l}\text { Follow-up } \\
\text { (FU) }(\%)\end{array}$ & $\begin{array}{l}\text { Difference } \\
\text { Pre to Post (\%) }\end{array}$ & $\begin{array}{l}\text { Difference } \\
\text { Pre to FU (\%) }\end{array}$ & $\begin{array}{l}\text { Difference } \\
\text { Post to FU (\%) }\end{array}$ \\
\hline \multicolumn{7}{|l|}{ Knowledge of typical development } \\
\hline Age when children can speak $5-10$ words & 55.75 & 71.34 & 70.97 & +15.59 & +15.22 & -0.37 \\
\hline Age when children engage in pretend play & 26.74 & 48.47 & 40.32 & +21.72 & +13.58 & -8.14 \\
\hline Age when children point to objects & 38.73 & 78.05 & 54.84 & +39.32 & +16.11 & -23.21 \\
\hline Age when children make regular eye contact & 84.48 & 83.85 & 85.48 & -0.63 & +1.00 & +1.63 \\
\hline Age when children respond to name & 72.99 & 62.20 & 69.35 & -10.79 & -3.63 & +7.16 \\
\hline Age when children imitate others' actions & 20.69 & 30.49 & 24.19 & +9.80 & +3.50 & -6.29 \\
\hline \multicolumn{7}{|l|}{ Knowledge of early signs (Auckland only) } \\
\hline \multicolumn{7}{|l|}{ Key signs } \\
\hline Pointing to share interest & 70.52 & 95.12 & 91.67 & +24.60 & +21.15 & -3.46 \\
\hline Rarely makes spontaneous eye contact & 93.68 & 98.17 & 100 & +4.49 & +6.32 & +1.83 \\
\hline Does not use age appropriate gestures & 72.52 & 94.35 & 80.65 & +21.84 & +8.13 & -13.71 \\
\hline \multicolumn{7}{|l|}{ Behaviours that are not key signs } \\
\hline Delayed gross motor skills & 74.05 & 91.94 & 93.55 & +17.89 & +19.50 & +1.61 \\
\hline Above average cognitive abilities & 65.65 & 92.74 & 93.55 & +27.09 & +27.90 & +0.81 \\
\hline Tantrums & 75.27 & 91.46 & 88.33 & +16.18 & +13.05 & -3.13 \\
\hline Hyperactivity & 66.09 & 93.29 & 90.00 & +27.20 & +23.91 & -3.29 \\
\hline \multicolumn{7}{|l|}{ General autism knowledge } \\
\hline \multicolumn{7}{|l|}{ Correct responses to true statements } \\
\hline Children can be identified by 24 months & 48.54 & 93.29 & 93.22 & +44.75 & +44.68 & -0.07 \\
\hline Occurs more in boys than girls & 49.42 & 92.07 & 58.33 & +42.65 & +8.91 & -33.74 \\
\hline Is a neurodevelopmental condition & 70.76 & 92.59 & 95.00 & +21.83 & +24.24 & +2.41 \\
\hline \multicolumn{7}{|l|}{ Correct responses to false statements } \\
\hline More common in higher SES areas & 59.65 & 84.66 & 81.67 & +25.01 & +22.02 & -3.00 \\
\hline Can be cured & 69.46 & 93.90 & 98.31 & +24.44 & +28.84 & +4.40 \\
\hline "Just" an intellectual disability & 73.53 & 88.89 & 88.33 & +15.36 & +14.80 & -0.56 \\
\hline
\end{tabular}

SES socioeconomic status

remained above pre-workshop levels $(Z=-2.736, p=0.006)$. Participant confidence increased for each item from preworkshop to post-workshop/follow-up and decreased for all items from post-workshop to follow-up.

\section{Acceptability of the SACS-R Tool}

Table 3 shows participants' mean Likert scale scores for each acceptability item and Fig. 2 shows their overall perceived acceptability of the SACS-R tool at each time-point. Overall acceptability significantly decreased from post-workshop to follow-up $(Z=-3.714, p>0.001)$, as did participant agreement with each acceptability item.

\section{Correlations}

Spearman's correlations between each subscale and both time in role and time as a nurse are presented in Tables $\mathrm{S} 1$ and S2. There were significant weak positive correlations between time in role and confidence at pre- and post-workshop and between time in role and knowledge of typical development at pre-workshop and follow-up. There was a significant moderate positive correlation between time as a nurse and confidence at pre-workshop and a weak positive correlation between time as a nurse and knowledge of typical development post-workshop. There were no other significant correlations.

\section{Discussion}

Universal developmental surveillance plays an important role in early diagnosis and timely access to early intervention. This study was the first to examine developmental surveillance training for NZ WCTO nurses. Our results suggest that the nurses increased their knowledge of typical social attention and communication development, early signs of autism, and general autism knowledge immediately following the training. Their confidence in identifying signs of autism in children aged 12,18, 24, and 30 months and in 
Table 3 Mean Likert Scale Scores and standard deviations for each confidence and acceptability item at pre-workshop (confidence only), postworkshop, and follow-up

\begin{tabular}{|c|c|c|c|c|c|c|}
\hline & Pre-workshop & Post-workshop & Follow-up (FU) & $\begin{array}{l}\text { Mean difference } \\
\text { Pre to Post }\end{array}$ & $\begin{array}{l}\text { Mean difference } \\
\text { Pre to FU }\end{array}$ & $\begin{array}{l}\text { Mean difference } \\
\text { Post to FU }\end{array}$ \\
\hline \multicolumn{7}{|l|}{ Confidence } \\
\hline $\begin{array}{l}\text { Confidence in identifying signs at } \\
12 \text { months }\end{array}$ & $2.60(1.24)$ & $5.06(0.69)$ & $4.77(0.72)$ & +2.46 & +2.17 & -0.29 \\
\hline $\begin{array}{l}\text { Confidence in identifying signs at } \\
18 \text { months }\end{array}$ & $2.99(1.26)$ & $5.15(0.64)$ & $4.91(0.80)$ & +2.16 & +1.92 & -0.24 \\
\hline $\begin{array}{l}\text { Confidence in identifying signs at } \\
24 \text { months }\end{array}$ & $3.67(1.25)$ & $5.25(0.59)$ & $5.15(0.78)$ & +1.58 & +1.48 & -0.10 \\
\hline $\begin{array}{l}\text { Confidence in identifying signs at } \\
30 \text { months }\end{array}$ & $4.01(1.28)$ & $5.18(0.82)$ & $5.17(0.72)$ & +1.18 & +1.16 & -0.02 \\
\hline $\begin{array}{l}\text { Confidence in discussing concerns } \\
\text { with parents }\end{array}$ & $3.55(1.28)$ & $4.86(0.70)$ & $4.71(0.92)$ & +1.31 & +1.17 & -0.14 \\
\hline \multicolumn{7}{|l|}{ Acceptability of the SACS-R tool } \\
\hline Easy to incorporate into practice & & $5.22(0.78)$ & $4.78(0.98)$ & & & -0.44 \\
\hline Will regularly use & & $5.33(0.80)$ & $4.74(1.23)$ & & & -0.59 \\
\hline $\begin{array}{l}\text { Help me to understand autism in } \\
\text { infancy and toddlerhood }\end{array}$ & & $5.62(0.55)$ & $5.58(0.05)$ & & & -0.03 \\
\hline $\begin{array}{l}\text { Parents will be comfortable with } \\
\text { the SAC-R }\end{array}$ & & $4.98(0.66)$ & $4.64(0.88)$ & & & -0.34 \\
\hline $\begin{array}{l}\text { SAC-R is appropriate for Māori } \\
\text { whānau }\end{array}$ & & $5.23(0.71)$ & $4.86(1.06)$ & & & -0.39 \\
\hline
\end{tabular}

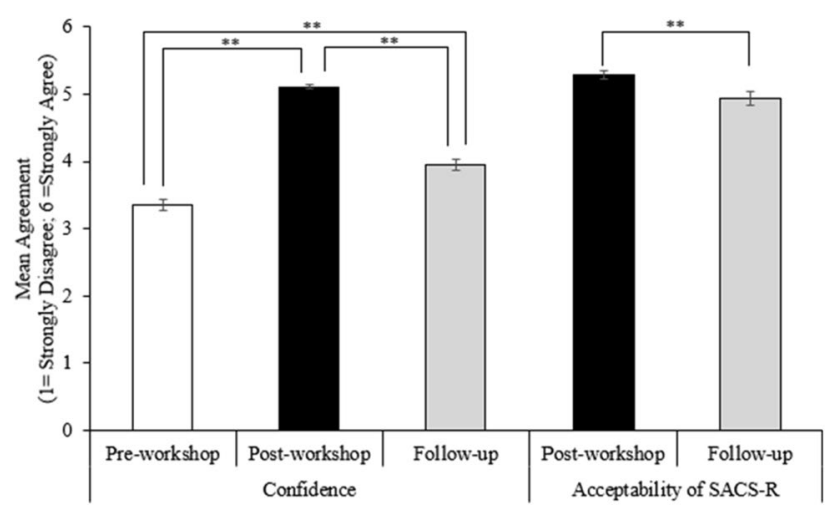

Fig. 2 Mean likert scale scores $(1=$ strongly disagree; $6=$ strongly agree) for confidence and acceptibility of the SACS-R tool at preworkshop, post-workshop, and follow-up. Note: $* * p<0.001$

raising these concerns with parents also increased. They also generally found the SACS-R tool to be highly acceptable.

These findings align with previous research, which found that nurses and educators had positive perceptions of the SACS-R training/tool and that their confidence in identifying and discussing early signs with parents increased following training (Barbaro et al., 2011; Mozolic-Staunton et al., 2021; Shrestha et al., 2021). Shrestha et al. (2021) similarly found that nurses' knowledge improved after participation in the SACS-R workshop. The three countries represented in the current and previous research (NZ, Australia, and Nepal) have vastly different demographic characteristics, culture, health systems, and available funding for developmental surveillance. Thus, it is promising that SACS-R training and tool were perceived as feasible and acceptable across all studies.

Nurses' general autism knowledge, confidence, and perceived acceptability of the SACS-R tool remained relatively high at follow-up but there were some decreases in these three areas compared to post-workshop. This is in contrast to Shrestha et al. (2021), who did not find any decreases from post-workshop to follow-up. Following the initial training, nurses in the Shrestha et al. study participated in monthly meetings in which they discussed cases and issues in implementing the SACS-R, while nurses in the current study did not. These monthly meetings may have been crucial in maintaining nurses' knowledge and confidence following the workshop. The findings of the current study therefore indicate that while the 1-day training was effective in increasing nurses' early autism knowledge and confidence, it should ideally be complemented with additional, ongoing support.

Participants who had spent longer in their role or as a nurse were more confident in identifying and discussing early signs, prior to the workshop than those with less experience. Although more experienced nurses scored higher on knowledge of typical development at some time-points, level of experience was not related to nurses' knowledge of early signs of autism or general autism knowledge. This may be because while many of 
the nurses had numerous years of experience examining developmental milestones during well-child checks, most had never received any formal autism training. Several previous studies have also found that experienced clinicians often have limited knowledge of autism (e.g., Ben-Sanson et al., 2018; Shrestha et al., 2021; Tilahun et al., 2019). Thus, nurses of all levels of experience and confidence may benefit from autism-specific training.

The current study had some limitations to note. The response rate for the follow-up survey was low, possibly due in part to Covid-19 lockdowns, particularly in the Auckland cohort as there were more strict lockdowns in this area compared to Wellington. The follow-up period was also 3 months in the Wellington sample and 8 months in the Auckland sample, although no significant differences existed between these two locations. The study also lacked a comparison group who did not participate in the training. Further, the data for knowledge of early signs in the Wellington cohort was not useable. Although participant-reported autism knowledge and confidence was related to accuracy of early identification in previous research (Ben-Sasson et al., 2018), we did not directly examine referral rates or the psychometrics properties of the SACS-R within this NZ sample. Thus, it is not clear whether the nurses became more accurate at identifying early signs of autism in their day-to-day practice. We also did not assess the impact of the training on children and families.

The results of this study suggest that NZ WCTO nurses increased their autism knowledge and confidence in identifying and discussing early signs of autism during developmental surveillance training; they also found the SACS-R to be highly acceptable. This suggests that implementation of the SACS-R in a NZ context is feasible and acceptable. Larger scale research on the implementation of SACS-R in NZ, including investigation of its psychometric properties, effects of ongoing training, and referral pathways, is warranted.

Supplementary Information The online version contains supplementary material available at https://doi.org/10.1007/s10803-021-05344-7.

Acknowledgments This work was supported in part by an Emerging Researcher Grant from Victoria University of Wellington (\#222692; HW) and funding from Auckland University of Technology (DS). Jake Meads and Regina Singh assisted with data collection and analysis.

Author Contributions HW: Assisted with the design, data collection, and data analysis, and drafted and edited the study manuscript. DS: Assisted with the design, data collection and analysis and provided edits on all versions of the manuscript. LvdM: Assisted with the design and data collection, and provided edits on all versions of the manuscript. NPH: Assisted with data collection, data analysis, and drafting of methods and results. EW: Assisted with data collection, data analysis, and drafting of methods and results. JB: Assisted with design and data analysis, provided expert advice regarding the SACS tool, delivered the training, and provided edits on all versions of the manuscript.

\section{Declarations}

Conflict of interest The authors report no conflicts of interest.

Ethical Approval Ethical clearance was granted by the Victoria University of Wellington Human Ethics Committee (\#27192).

\section{References}

American Academy of Pediatrics. (2007). Identifying infants and young children with developmental disorders in the medical home: An algorithm for developmental surveillance and screening. Pediatrics, 118(1), 405-420. https://doi.org/10.1542/peds. 2006-1231

American Psychiatric Association. (2013). Diagnostic and statistical manual of mental disorder (5th ed.). American Psychiatric Association. https://doi.org/10.1176/appi.books.9780890425 596

Atun-Einy, O., \& Ben-Sasson, A. (2018). Pediatric allied healthcare professionals' knowledge and self-efficacy regarding ASD. Research in Autism Spectrum Disorders, 47, 1-13. https://doi. org/10.1016/j.rasd.2017.12.001

Barbaro, J., \& Dissanayake, C. (2009). Autism spectrum disorders in infancy and toddlerhood: A review of the evidence on early signs, early identification tools, and early diagnosis. Journal of Developmental \& Behavioral Pediatrics, 30(5), 447-459.

Barbaro, J., \& Dissanayake, C. (2010). Prospective identification of autism spectrum disorders in infancy and toddlerhood using developmental surveillance: The social attention and communication study. Journal of Developmental \& Behavioral Pediatrics, 31(5), 376-385. https://doi.org/10.1097/DBP.0b013e3181df7f3c

Barbaro, J., \& Dissanayake, C. (2013). Early markers of autism spectrum disorders in infants and toddlers prospectively identified in the Social Attention and Communication Study. Autism: the International Journal of Research \& Practice, 17(1), 64-86. https://doi.org/10.1177/1362361312442597

Barbaro, J., \& Dissanayake, C. (2017). Diagnostic stability of autism spectrum disorder in toddlers prospectively identified in a community-based setting: Behavioural characteristics and predictors of change over time. Autism, 21(7), 830-840. https://doi.org/10. $1177 / 1362361316654084$

Barbaro, J., Ridgway, L., \& Dissanayake, C. (2011). Developmental surveillance of infants and toddlers by maternal and child health nurses in an Australian community-based setting: Promoting the early identification of autism spectrum disorders. Journal of Pediatric Nursing, 26(4), 334-347. https://doi.org/10.1016/j. pedn.2010.04.007

Ben-Sasson, A., Atun-Einy, O., Yahav-Jonas, G., Lev-On, S., \& Gev, T. (2018). Training physical therapists in early ASD screening. Journal of Autism and Developmental Disorders, 48(11), 3926-3938. https://doi.org/10.1007/s10803-018-3668-9

Bent, C., Dissanayake, C., \& Barbaro, J. (2015). Mapping the diagnosis of autism in children under 7 years in Australia: 20102012. Medical Journal of Australia, 202, 317-320. https://doi. org/10.5694/mja14.00328

Cohen, J. (1988). Statistical power analysis for the behavioral sciences (2nd ed.). Erlbaum.

Fuller, E. A., \& Kaiser, A. P. (2019). The effects of early intervention on social communication outcomes for children with autism 
spectrum disorder: A meta- analysis. Journal of Autism and Developmental Disorders, 50(55), 1683-1700. https://doi.org/ 10.1007/s10803-019-03927-z

Maenner, M. J., Shaw, K. A., \& Baio, J. (2020). Prevalence of autism spectrum disorder among children aged 8 years-autism and developmental disabilities monitoring network, 11 sites, United States, 2016. MMWR Surveillance Summaries. https://doi.org/ 10.15585/mmwr.ss6904a1

Mozolic-Staunton, B., Barbaro, J., Yoxall, J., \& Donelly, M. (2021). Monitoring children's development in early childhood education settings to promote early detection of autism. Australasian Journal of Early Childhood, 46(2), 163-178. https://doi.org/10. 1177/1836939121998085

Mozolic-Staunton, B., Donelly, M., Yoxall, J., \& Barbaro, J. (2020). Early detection for better outcomes: Universal developmental surveillance for autism across health and early childhood education settings. Research in Autism Spectrum Disorders, 71, 1-14. https://doi.org/10.1016/j.rasd.2019.101496

Oberklaid, F., Baird, G., Blair, M., Melhuish, E., \& Hall, D. (2013). Children's health and development: Approaches to early identification and intervention. Archives of Disease in Childhood, 98(12), 1008-1011. https://doi.org/10.1136/archdischild-2013-304091

Shrestha, R., Barbaro, J., \& Dissanayake, C. (2021). Changes in knowledge on the signs of autism in young children (11-30 months) among female community health volunteers in Nepal. Journal of Autism and Developmental Disorders. https://doi.org/10.1007/ s10803-021-04944-7 advance online publication.

Tilahun, D., Fekadu, A., Tekola, B., Araya, M., Roth, I., Davey, B., Hanlon, C., \& Hoekstra, R. A. (2019). Ethiopian community health workers' beliefs and attitudes towards children with autism: Impact of a brief training intervention. Autism, 23(1), 39-49. https://doi.org/10.1177/1362361317730298 van't Hof, M., Tisseur, C., van Berckelear-Onnes, I., van Nieuwenhuyzen, A., Daniels, A. M., Deen, M., Hoek, H. W., \& Ester, W. A. (2020). Age at autism spectrum disorder diagnosis: A systematic review and meta-analysis from 2012 to 2019. Autism, 25(4), 862-873. https://doi.org/10.1177/1362361320971107

Whitehouse, A. J., Varcin, K. J., Alvares, G. A., Barbaro, J., Bent, C., Boutrus, M., Chetcuti, L., Cooper, M. N., Clark, A., Davidson, E., Dimov, S., Dissanayake, C., Doyle, J., Grant, M., Iacono, T., Maybery, M., Pillar, S., Renton, M., Rowbottam, C.,...Hudry, K. (2019). Pre-emptive intervention versus treatment as usual for infants showing early behavioral risk signs of autism spectrum disorder: A single-blind, randomised controlled trial. The Lancet Child \& Adolescent Health, 3(9), 605-615. https://doi.org/10. 1016/s2352-4642(19)30184-1

Yuen, T., Penner, M., Carter, M. T., Szatmari, P., \& Ungar, W. J. (2018). Assessing the accuracy of the modified checklist for autism in toddlers: A systematic review and meta-analysis. Developmental Medicine \& Child Neurology, 60(11), 1093-1100. https://doi.org/ 10.1111/dmen.13964

Zwaigenbaum, L., Bauman, M. L., Choueiri, R., Kasari, C., Carter, A., Granpeesheh, D., \& Pierce, K. (2015). Early intervention for children with autism spectrum disorder under 3 years of age: Recommendations for practice and research. Pediatrics, 136(Suppl. 1), S60-S81. https://doi.org/10.1542/peds.2014-3667e

Publisher's Note Springer Nature remains neutral with regard to jurisdictional claims in published maps and institutional affiliations. 